\title{
Overprescribing iron tablets to elderly people in Sweden
}

\author{
PETER REIZENSTEIN, \\ MARTA PENCHANSKY
}

GUNNAR LJUNGGREN, BJÖRN SMEDBY, INGEGERD AGENÄS,

British Medical fournal, 1979, 2, 962-963

\section{Summary and conclusions}

Iron should not be prescribed to middle-aged men or older women with anaemia unless the possibility that the iron deficiency is caused by a gastrointestinal tumour has been considered. Thus the prescribing of iron to elderly people was investigated by studying four different prescription statistics and by reviewing records. Over one in 10 women aged over 65 were prescribed iron tablets. Men and women in the oldest age groups were prescribed iron most frequently. The reasons for prescribing iron were examined at a rural health centre. Out of 327 records of patients who were prescribed iron during 1975, 157 were randomly selected and reviewed. Only 18 out of $48(38 \%)$ patients aged 45-75 (men) and 55-75 (women) and 29 out of $109(27 \%)$ aged over 75 years had probable or possible iron-deficiency anaemia as established from the records. Only nine $(19 \%)$ of the younger patients had a plausible reason for the anaemia other than a bleeding tumour. Ten $(9 \%)$ of the older patients were considered to be inoperable cases. Thus, according to the records, only $18(17 \%)$ of the patients over 75 years and nine $(19 \%)$ of those in the younger age group should have been prescribed iron. About $70 \%$ of all the patients were considered not to have iron deficiency; $7 \%$ had had iron deficiency previously, and $20 \%$ probably had anaemia as a result of chronic disease; for $43 \%$ no real reason for the iron prescription could be found in the record.

Thus it is concluded that iron is overprescribed in Sweden, particularly for elderly people. It should not be prescribed until the possibility of a bleeding gastrointestinal tumour has been excluded.

\section{Introduction}

For many years the Swedish drug industry has emphasised the risks of iron deficiency. This propaganda may be connected with the comparatively high sale of iron tablets in Sweden (table I).

TABLE I-Yearly sale of iron in Sweden and other countries expressed as crowns per person

\begin{tabular}{lr}
\hline Sweden & $2 \cdot 0$ \\
Great Britain & $0 \cdot 68$ \\
Germany & $0 \cdot 64$ \\
France & $0 \cdot 4$ \\
\hline
\end{tabular}

The high consumption of iron in Sweden has advantages and disadvantages: iron deficiency has become less common, ${ }^{1}$ but overprescribing of iron tablets to elderly people seems to occur. ${ }^{2}$ Iron deficiency in older people is rarely due to poor diet. ${ }^{3-6}$ Iron intake does decrease with age ${ }^{\prime}$ but is not correlated with the haemoglobin concentration. Iron deficiency in older people, with or without anaemia, is normally a sign of bleeding, sometimes from a gastrointestinal tumour. ${ }^{4}$ For that reason the source of the bleeding should always be looked for when irondeficiency anaemia is found in a man or postmenopausal woman. ${ }^{5} 689$ To recommend or prescribe iron tablets for only tiredness or anaemia is not justified..$^{6}{ }^{9} \mathrm{We}$ performed this study to see whether such prescribing occurs. Interestingly, we chose to study an area of Sweden very close to that where 32 years ago iron-deficiency anaemia was originally found to be prevalent. ${ }^{10}$

\section{Methods}

We studied the prescribing of iron tablets to elderly people in five ways. (1) From a study of living conditions in Sweden performed by the National Central Bureau of Statistics we obtained the proportion of people who stated that they had taken iron tablets during the two weeks preceding the interview. ${ }^{11}$ (2) The Department of Drugs examined a random sample of $0.35 \%$ of the total number of prescriptions for the whole country and established the number of elderly people for whom iron had been ordered and bought. ${ }^{12}$ (3) From the 1976 prescription statistics from the county of Jämtland in Sweden we calculated the proportions of people in different age groups who had been ordered iron and bought it. ${ }^{13}$ (4) From the computerised prescription data from the pharmacy in Tierp, a rural health centre equipped for research, we calculated the proportions of people in different age groups who had been ordered iron and bought it in 1975.

(5) We reviewed case records to see why iron was prescribed.

The record review (5) was performed as follows. For certain years all prescriptions at the pharmacy in Tierp were recorded.14 From these data we selected two groups of patients out of those who were ordered iron in therapeutic amounts during 1975. Patients who had received preparations containing prophylactic amounts of iron were excluded. One group consisted of all 109 patients in the record aged 75 years and older. The second group consisted of a sample of men aged between 45 and 74 years and women aged between 55 and 74 years: we studied 48 records in this group. The Tierp health centre has a proper record library with professionally typed records. All results of laboratory and $x$-ray examinations are always included in the record. We studied results of haemoglobin examinations carried out when the prescription was made, results of estimation of iron and transferrin concentrations in serum and of examinations of the gastrointestinal tract, and any further information in the record that seemed relevant.

We also performed a pilot study of over-the-counter sales, in which 40 customers who bought iron during a two-week period answered some questions.

\section{Results}

Table II shows that in the different studies (but excluding the record review) between 6.7 and $12.8^{\circ}$ of all older women and between 3.8 and $5.9 \%$ of all men had been ordered and had bought iron tablets. The proportion of men who are prescribed iron increases with age, as does the proportion of women after the age of 60 (figure). In younger women the proportion prescribed iron is highest around the age of $30 .^{15}$

Table III shows the reasons for prescribing iron. Only $29\left(27^{\circ}\right)$ of all patients over 75 years and $18(38 \%)$ of all patients under 75 years had probable or possible iron-deficiency anaemia. Of these, eight $\left(7_{0}^{\circ}\right)$ in the older group and nine $(19 \%)$ in the younger group

Division of Haematology, Karolinska Hospital, Stockholm, Sweden PETER REIZENSTEIN, MD, head of division

GUNNAR LJUNGGREN, MD, resident

MARTA PENCHANSKY, MD, visiting scientist

Department of Social Medicine, University of Uppsala, Uppsala, Sweden

BJÖRN SMEDBY, MD, assistant professor

Department of Drugs, National Board of Health and Welfare, Uppsala, Sweden

INGEGERD AGENÄS, councillor .

列


TABLE II-Proportions of people given iron prescriptions derived from four different sets of statistics

\begin{tabular}{|c|c|c|c|}
\hline Method of study & $\underset{\text { (years) }}{\text { Age }}$ & $\begin{array}{c}\text { "., of } \\
\text { women given } \\
\text { iron } \\
\text { prescriptions }\end{array}$ & $\begin{array}{c}\text { "o, of } \\
\text { men given } \\
\text { iron } \\
\text { prescriptions }\end{array}$ \\
\hline $\begin{array}{c}\text { Data on Swedish living conditions } \\
1974^{11}\end{array}$ & $65-74$ & $6 \cdot 7$ & $5 \cdot 0$ \\
\hline $\begin{array}{l}\text { Random sample of prescriptions, } \\
1976^{12}\end{array}$ & $65-74$ & $12 \cdot 8$ & 5.9 \\
\hline $\begin{array}{l}\text { Prescriptions in Jämtland, } 1976 \\
\text { Prescriptions at pharmacy in }\end{array}$ & $60-69$ & 9.6 & $4 \cdot 2$ \\
\hline $\begin{array}{l}\text { Prescriptions at pharmacy in } \\
\text { Tierp, } 1975\end{array}$ & $\begin{array}{l}>65 \text { (women }) \\
>45(\text { men })\end{array}$ & $12 \cdot 3$ & $3 \cdot 8$ \\
\hline
\end{tabular}
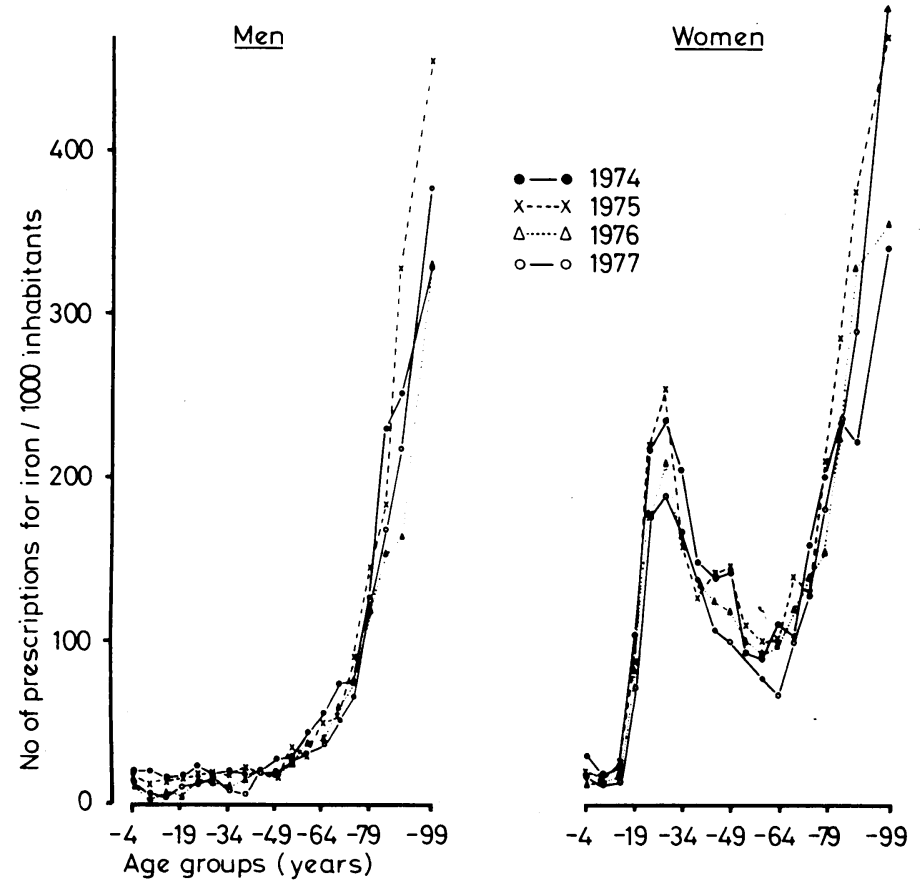

Numbers of prescriptions of iron tablets/1000 people in different age groups of men and women. ${ }^{15}$

TABLE III-Reasons for prescribing iron in the 157 records examined. Figures are numbers $\left({ }^{\circ}\right)$ of cases

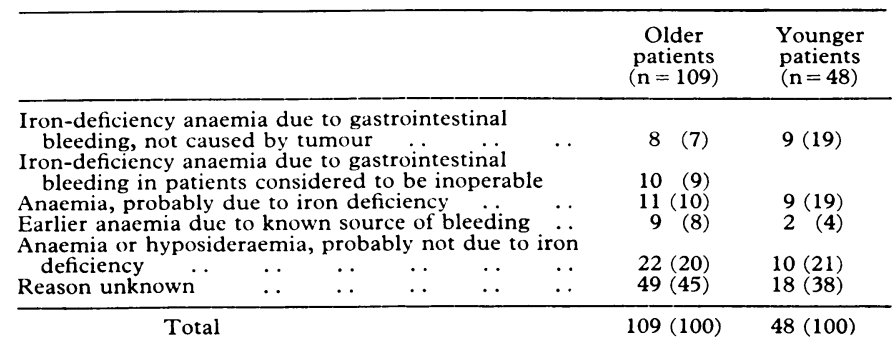

had a plausible reason for iron deficiency other than a bleeding gastrointestinal tumour. Another $10\left(9^{\circ}{ }_{0}\right)$ of the older patients may have been considered to be inoperable cases. Thus only $18\left(17^{\circ}{ }_{0}\right)$ of the patients over 75 years and nine $\left(19^{\circ}{ }_{0}\right)$ of those between 45 (men) or 55 (women) and 75 years who got prescriptions for iron tablets ought to have got them without further investigations for the source of the bleeding.

Twenty-two $\left(20^{\prime \prime}{ }_{1}\right)$ of the patients aged 75 years and older and 10 $\left(21^{\circ}{ }_{0}\right)$ of those aged under 75 years had anaemia or hyposideraemia that we did not believe was caused by iron deficiency. These patients had diseases that often cause so-called anaemia of chronic disease, such as rheumatoid arthritis, renal failure, myeloma, or pneumonia. Iron treatment is in general not considered to be effective in these types of anaemia

From the records we could not find any reason for prescribing iron for $49\left(45^{\circ}{ }_{0}\right)$ of the patients aged over 75 and $18\left(38_{\%}^{\circ}\right)$ of those aged under 75 . These patients could be divided into two subgroups: 18 had no anaemia according to the record, and we guessed that fatigue had been the indication for the iron prescription; and for 49 no laboratory data could be found, so that the same reason for prescribing iron could probably be assumed.

Results of pharmacy inquiry - Swedish sales data for 1977 showed that the pharmacies sold 938000 packages of iron tablets: 85000 to hospitals, 597000 on prescription, and $256000\left(30_{\%}^{\circ}\right)$ over the counter. Of the customers who answered our questions, one-quarter said that they had previously been ordered to take iron and one-half that they were tired and considered iron to be strengthening.

\section{Discussion}

The proportions of middle-aged and old people prescribed iron tablets, which were derived from four different sets of statistics, were all high. In middle-aged men the proportion with prescriptions for iron tablets was five times the proportion estimated to have iron deficiency $\left(1^{\circ}{ }_{0}\right) .{ }^{16}$ Only $27\left(17^{\circ}{ }_{0}\right)$ of the records examined contained the reason for prescribing iron. The results given here are our interpretations of the records. In each case there may have been reasons known to the prescribing doctor, based on personal knowledge of the patient, that were not in the record. We did not discuss each case with the prescribing doctor, but a joint discussion of our results elicited no reason for the prescriptions other than the ones mentioned.

If we assume that patients with gastrointestinal tumours are prescribed iron as often as people without, we can estimate that, among the about 185000 middle-aged and elderly people in Sweden (men over 45 and women over 55) who are prescribed iron every year, there are about 150 men and 300 women with gastrointestinal malignancies. ${ }^{1718}$ Therefore, any prescribing information about iron tablets should emphasise that iron should be prescribed, particularly to elderly people, only after the doctor has considered the possibility that a bleeding gastrointestinal tumour may be present.

This investigation was performed in connection with a project on the quality and cost of medical care and with support from the Swedish Medical Council (project 27x-4734).

We thank the chief, Ms Lindskog, and the staff at the pharmacy Vita Björnen, Stockholm; Mr A Wessling at the Swedish National Pharmacy Co-operation, Stockholm; and the head physician Bengt Berg, the doctors, and other staff at the Health Centre at Tierp for their help.

\section{References}

${ }^{1}$ Hallberg, L, et al, Läkartidningen, 1977, 17, 1719.

2 Reizenstein, P, et al, in Diagnostics and Treatment of Iron Deficiency, ed L Hallberg and L Sölvell, p 25. Gothenburg, Hässle, 1978.

${ }^{3}$ Evans, D M D, Gerontologia Clinica, 1971, 13, 12.

${ }^{4}$ Bedford, P D, and Wollner, L, Lancet, 1958, 1, 1144.

5 Will, G, and Groden, B, Scottish Medical fournal, 1965, 10, 21.

${ }^{6}$ Wintrobe, M M, Clinical Haematology, 5th edn, p 773. Philadelphia, Lea and Febiger, 1961.

? Hallberg, L, and Högdal, A-M, Gerontologia Clinica, 1971, 13, 31.

${ }^{8}$ Lawson, I, Gerontologia Clinica, 1960, 2, 87.

${ }^{9}$ Reizenstein, P, Haematology, 2nd edn, p 22. Lund, Student-litteratur, 1975.

10 Waldenström, J, Acta Medica Scandinavica, 1946, Suppl 170, p 252.

${ }^{11}$ National Central Bureau of Statistics, Living Conditions I. Stockholm, Swedish Official Statistics. Liber Stockholm, 1976.

12 Wessling, A, Swedish National Pharmacy Co-operation Statistics, personal communication, 1978.

${ }^{13}$ Boethius, G, personal communication, 1978.

${ }^{14}$ Berfenstam, R, and Smedby, B, Socialmedicinsk Tidskrift, 1978, 55, 417.

15 Wessling, A, Swedish National Pharmacy Co-operation Statistics, personal communication.

${ }_{16}^{16}$ Hedstrand, H, and Killander, A, Acta Medica Scandinavica, 1977, 19, 417.

17 National Board of Health and Welfare, The Cancer Registry: Cancer Incidence in Sweden 1968. Stockholm, National Board of Health and Welfare, 1971.

18 National Central Bureau of Statistics, Statistical Abstract of Sweden 1974. Stockholm, Swedish Official Statistics. Liber Stockholm, 1974.

(Accepted 7 August 1979) 